\title{
PIRMĄ KARTĄ NUSTATYTI ANTINKSČIŲ DARINIAI: 2010 IR 2014 METU IŠTYRIMO TAKTIKOS PALYGINIMAS
}

\author{
Lina Ščerbinskaitė $\dot{1}^{1,2}$, Aušra Bradulskytè ${ }^{1,2}$, Milda Girdžiūtè $\dot{e}^{3}$ Vilija Guntaite் \\ Žydrūnè Visockiené $\dot{e}^{1,2}$ \\ ${ }^{l}$ Vilniaus universiteto Medicinos fakultetas, ${ }^{2}$ Vilniaus universiteto ligoninè Santaros klinikos, \\ ${ }^{3}$ Vš I Antakalnio poliklinika, ${ }^{4}$ Respublikinè Šiauliu ligoninè
}

Raktažodžiai: antinksčių dariniai, kompiuterinè tomografija, deksametazono supresijos mèginys, metanefrinu koncentracijos kraujyje tyrimas, aldosteroma.

\begin{abstract}
Santrauka
Antinksčų dariniai yra gana dažnas radinys, nustatomas atliekant radiologinius vidaus organu tyrimus. Siekiant nustatyti darinio aktyvumą, reikalingas hormoninis ištyrimas. Šio tyrimo tikslas buvo ịvertinti pacientų, kuriems pirmą kartą nustatytas antinksčių darinys 2010 arba 2014 metais, hormoninio ištyrimo taktiką. Šiais laikotarpiais nustatyti 383 dariniai, ị galutinę analizę atrinkti 195 pacientai. Dauguma darinių rasti atsitiktinai ir beveik pusé jų nesukẻlé jokių simptomų. Didžiausią pacientų dalị sudaré moterys, dariniai dažniausiai nustatyti atliekant kompiuterinès tomografijos (KT) tyrimą, dauguma jų - kairiajame antinkstyje. Palyginus hormoninių tyrimų (kortizolio, aldosterono, metanefrino, normetanefrino, dopamino, adrenalino ir noradrenalino kraujyje ar šlapime) atlikimo dažnį 2010 ir 2014 metų pacientų grupèse stebèta, kad šie tyrimai 2014 metais buvo atlikti dažniau. Pagerejjus hormoniniam ištyrimui, 2014 metais nustatyta dvigubai daugiau aldosteromų, tačiau kitų hormoniškai aktyvių darinių dažniai nesiskyrè.
\end{abstract}

\section{Ivadas}

İvairių studijų duomenimis, atliekant radiologinius tyrimus dariniai antinksčiuose vidutinio amžiaus žmonių grupeje nustatomi iki 5\%, pagyvenusių - iki 10\% atvejų [1-6], o vaikysteje ir paauglysteje pasitaiko ypač retai [7]. Autopsijų duomenimis, kliniškai nepasireiškusių darinių antinksčiuose dažnis svyruoja nuo 1,0 iki 8,7\% (vidutiniškai apie $2 \%$ ) ir didejja su amžiumi [1-3].

Radus darinị antinkstyje, svarbiausi uždaviniai - atskir- ti gerybini procesą nuo piktybinio bei funkciškai neaktyvų darinį nuo aktyvaus [8].

Darinio piktybiškumas iš dalies gali būti vertinamas pagal vaizdinių tyrimų rezultatus. Kompiuterinès tomografijos (KT) tyrimas be kontrasto rekomenduojamas kaip pirmo pasirinkimo tyrimas, norint ịvertinti darinio dydi ir charakteristikas [7-9]. Gerybinèms adenomoms būdingas didesnis intraląstelinis lipidų kiekis, todèl atliekant KT be kontrasto jų tankis mažesnis nei 10 Hounsfield vienetų (HV) ir, diferencijuojant nuo piktybinio naviko, ši savybe pasižymi 96-100\% jautrumu ir 50-100\% specifiškumu [7]. Esant adenomos tankiui 20-40 HV rekomenduojama atlikti KT tyrimą su kontrastu. Didesnis nei 50\% kontrastinès medžiagos išplovimas po 10-15 minučių leidžia patikimai diagnozuoti gerybinę adenomą $[9,10]$. Ultragarsinis tyrimas nepadeda diferencijuoti gerybinio proceso nuo piktybinio, todèl kasdieneje praktikoje nerekomenduojamas, nors galètų būti naudingas dinamikoje vertinant darinio dydžio kitimus [7]. Magnetinio rezonanso tyrimas (MRT) nerekomenduojamas kasdienejje praktikoje, nors pasižymi dideliu jautrumu (84-100\%) ir specifiškumu (92-100\%) diferencijuojant nuo piktybinio naviko, turètų būti naudojamas tik išskirtiniais atvejais, pavyzdžiui, ịvertinant darinius antinksčiuose vaikams, paaugliams, něščioms ir jaunesniems nei 40 metų pacientams. Biopsija rekomenduojama atlikti tik tiems pacientams, kuriems prieš tai buvo nustatytas kitos lokalizacijos piktybinis navikas. Biopsijos jautrumas ir specifiškumas diagnozuojant piktybini antinksčių darinị siekia atitinkamai $73-100 \%$ ir $86-100 \%[7,9]$.

Atsitiktinai nustačius darini antinksčiuose, rekomenduojama privalomai ištirti dèl hormoninio aktyvumo, atmetant autonominę kortizolio ir katecholaminų sekreciją. Kortizolio sekrecijai įvertinti turi būti atliekamas1 mg deksametazono supresijos mėginys [9], kurio jautrumas ir specifiškumas siekia atitinkamai $73-100 \%$ ir 90\% [11]. Katecholaminų sintezè ir sekrecija vertinama tiriant frak- 
cionuotus metanefrinus paros šlapime, ir nors šio tyrimo jautrumas ir specifiškumas siekia net $95 \%$, kasdienineje praktikoje paros šlapimo rinkimas specialiomis sąlygomis apsunkina metodo pritaikymą. Daug plačiau tiriami laisvi plazmos metanefrinai ir noremetanefrinai, kadangi kraujo tyrimas gali būti imamas bet kuriuo metu [9], o jo jautrumas ir specifiškumas siekia atitinkamai $98 \%$ ir $89 \%$ [7, 12, 13]. Kortizolio ir katecholaminų sekrecija turi būti tiriama nepriklausomai nuo klinikiniu simptomų, o renino - aldosterono sistemos aktyvumas vertinamas tik tada, jeigu yra hipertenzija ir/ar hipokalemija. Ištyrus aldosterono ir renino koncentraciją, apskaičiuojamas aldosterono/renino santykis, kurio specifiškumas ir jautrumas autonominès aldosterono sekrecijos vertinimui siekia 90\% [11]. Ittariant hormoniškai aktyvią antinksčių žievès karcinomą, rekomenduojama ištirti antinksčių lytinių hormonų ir steroidų koncentracijas kraujyje [9].

Išsamus pacientų ištyrimas leidžia teisingai nustatyti

1 lentelè. Pagrindinių pacientų ir antinksčių darinių charakteristikų apžvalga

\begin{tabular}{|l|c|c|}
\hline & $\begin{array}{c}\mathbf{2 0 1 0} \mathbf{~ m .} \\
\mathrm{N}=54 \\
\mathrm{~N}(\%)\end{array}$ & $\begin{array}{c}\mathbf{2 0 1 4} \mathbf{~ m .} \\
\mathrm{N}=141 \\
\mathrm{~N}(\%)\end{array}$ \\
\hline Vyrai & $12(22,2)$ & $37(26,2)$ \\
\hline Moterys & $42(77,8)$ & $104(73,8)$ \\
\hline Amžius, metai & $61,4 \pm 12,9$ & $60,5 \pm 12,8$ \\
\hline Atsitiktinai rasti & $44(81,5)$ & $100(76,3)$ \\
\hline Tikslingai rasti & $10(18,5)$ & $31(23,7)$ \\
\hline Besimptomiai & $27(50,0)$ & $58(41,1)$ \\
\hline Simptominiai & $27(50,0)$ & $83(58,9)$ \\
\hline Iš jų: & & \\
\hline Hipertenzija & $22(81,5)$ & $71(85,5)$ \\
\hline $\begin{array}{l}\text { AKS pakilimo epizo- } \\
\text { dai }\end{array}$ & $12(44,4)$ & $32(38,5)$ \\
\hline Hipokalemija & $5(18,5)$ & $14(16,9)$ \\
\hline Svorio didejimas & $1(3,7)$ & $3(3,6)$ \\
\hline
\end{tabular}

2 lentelè. Antinksčių darinių radiologinis ištyrimas ir lokalizacija * $p=0,040$, lyginant 2010 ir 2014 metus

\begin{tabular}{|c|c|c|c|}
\hline & $\begin{array}{c}2010 \text { m. } \\
\text { N (\%) }\end{array}$ & $\begin{array}{c}2014 \text { m. } \\
\text { N (\%) }\end{array}$ & $\begin{array}{l}\text { Iš viso } \\
\mathrm{N}(\%)\end{array}$ \\
\hline $\begin{array}{l}\text { Darinys } \\
\text { nustatytas: } \\
\text { - UG }\end{array}$ & $14(25,9)$ & $32(23,7)$ & $46(24,3)$ \\
\hline$-\mathrm{KT}$ & $40(74,1)$ & $93(68,9)$ & $133(70,4)$ \\
\hline- MRT & $0(0,0)$ & $10(7,4)^{*}$ & $10(5,3)$ \\
\hline $\begin{array}{l}\text { Darinio } \\
\text { dydis, } \mathrm{mm}\end{array}$ & $23,8 \pm 16,7$ & $20,8 \pm 13,0$ & $21,7 \pm 14,2$ \\
\hline $\begin{array}{l}\text { Darinio } \\
\text { pusè }\end{array}$ & $\begin{array}{c}\text { Kairè } 21(38,9) \\
\text { Dešinè } 24(44,4) \\
\text { Abipus } 9(16,7)\end{array}$ & $\begin{array}{c}\text { Kaire } 62(44,6) \\
\text { Dešinė } 53(38,1) \\
\text { Abipus } 24(17,3)\end{array}$ & $\begin{array}{c}\text { Kairè } 83(43,0) \\
\text { Dešinè } 77(39,9) \\
\text { Abipus } 33 \\
(17,1)\end{array}$ \\
\hline
\end{tabular}

diagnozę ir pritaikyti adekvatu gydymą - chirurgini arba medikamentinị bei numatyti ilgalaikès priežiūros strategiją. Tam reikia darnaus endokrinologinès, radiologinès ir laboratorinès tarnybų darbo. Vilniaus universiteto ligonineje Santaros klinikose (VULSK) antinksčių darinius turintys pacientai tiriami ir gydomi nuolat, o 2012 metais ị klinikinę praktiką buvo įdiegtas plazmos metanefrinų tyrimas, kas ypač pagerino pacientų ištyrimą.

Tyrimo tikslas: įvertinti pacientų, kuriems pirmą kartą antinksčių darinys nustatytas 2010 arba 2014 metais, ištyrimo taktiką.

\section{Tyrimo medžiaga ir metodai}

I tyrimą buvo įtraukti pacientai, kuriems pagal Tarptautinès statistinès ligų ir sveikatos sutrikimų klasifikacijos dešimtojo pataisyto ir papildyto leidimo Australijos modifikaciją (TLK-10-AM) pirmą kartą buvo nustatyti diagnozių kodai D35.0; D44.1; E27.0; E27.5; E27.8; E27.9 2010 ir 2014 metais. Sudarytos dvi grupès, kurios palygintos tarpusavyje, vertinant:

- atliktus laboratorinius tyrimus, siekiant ịvertinti darinių antinksčiuose hormoninị aktyvumą: kortizolio, aldosterono, renino bei katecholaminų arba metanefrinų tyrimai,

- taikytus radiologinius tyrimus darinių vizualizacijai,

- darinių dydi, lokalizaciją, taikytą gydymo taktiką.

Papildomai analizei pacientai buvo sugrupuoti ir palyginti pagal:

- antinksčių darinių radimo būdą: atsitiktinis, kai dariniai antinksčiuose nustatyti atsitiktinai, atliekant vaizdinius tyrimus dèl kitų su antinksčiais nesusijusių priežasčių, ir tikslinis, kai tirta tikslingai, esant antinksčių išskiriamų hormonų hipersekrecijos klinikai,

3 lentelè. Ištyrimo dèl antinksčių darinių hormoninio aktyvumo dažnis 2010 ir 2014 metais

\begin{tabular}{|l|c|c|c|}
\hline & $\begin{array}{c}\mathbf{2 0 1 0} \mathbf{~ m} . \\
\text { N (\%) }\end{array}$ & $\begin{array}{c}\mathbf{2 0 1 4} \mathbf{~ m .} \\
\text { N (\%) }\end{array}$ & $\mathrm{p}$ \\
\hline Kortizolis & $17(31,5)$ & $59(41,8)$ & 0,184 \\
\hline Aldosteronas & $15(27,8)$ & $65(46,1)$ & 0,02 \\
\hline Reninas & $8(14,8)$ & $64(45,4)$ & $<0,001$ \\
\hline Tyrimai dèl feochromocitomos: & $15(27,8)$ & $68(48,2)$ & 0,01 \\
\hline - Metanefrinas kraujyje & $0(0)$ & $66(46,8)$ & $<0,001$ \\
\hline - Normetanefrinas kraujyje & $0(0)$ & $64(45,4)$ & $<0,001$ \\
\hline - Adrenalinas šlapime & $12(22,2)$ & $1(0,7)$ & $<0,001$ \\
\hline - Noradrenalinas šlapime & $12(22,2)$ & $1(0,7)$ & $<0,001$ \\
\hline - Adrenalinas kraujyje & $4(7,4)$ & $2(1,4)$ & 0,03 \\
\hline - Noradrenalinas kraujyje & $4(7,4)$ & $2(1,4)$ & 0,03 \\
\hline - Dopaminas kraujyje & $5(9,3)$ & $0(0)$ & $<0,001$ \\
\hline $\begin{array}{l}\text { Pacientai, kuriems nustačius } \\
\text { darinị antinkstyje, neatliktas } \\
\text { nei vienas antinksčių hormonuc } \\
\text { tyrimas }\end{array}$ & $21(38,9)$ & $23(16,3)$ & 0,001 \\
\hline
\end{tabular}


4 lentelè. Antinksčių hormonų tyrimų atlikimo dažnio palyginimas simptominių ir besimptomių pacientų grupèse

\begin{tabular}{|l|c|c|c|c|c|c|}
\hline Tyrimai & \multicolumn{2}{|c|}{ Simptominiai } & \multirow{2}{*}{$\mathrm{p}$} & \multicolumn{2}{c|}{ Besimptominiai } & \multirow{2}{*}{$\mathrm{p}$} \\
\cline { 2 - 3 } \cline { 5 - 6 } & $2010 \mathrm{~m}$. & $2014 \mathrm{~m}$. & & $2010 \mathrm{~m}$. & $2014 \mathrm{~m}$. & \\
& $\mathrm{N}=27$ & $\mathrm{~N}=83$ & & $\mathrm{~N}=27$ & $\mathrm{~N}=58$ & \\
& $\mathrm{~N}(\%)$ & $\mathrm{N}(\%)$ & & $\mathrm{N}(\%)$ & $\mathrm{N}(\%)$ & \\
\hline Kortizolis & $7(25,9)$ & $37(44,6)$ & 0,086 & $10(37)$ & $22(37,9)$ & 0,937 \\
\hline Aldosteronas & $7(25,9)$ & $39(46,9)$ & 0,054 & $8(29,6)$ & $26(44,8)$ & 0,183 \\
\hline Reninas & $6(22,2)$ & $38(45,8)$ & 0,03 & $2(7,4)$ & $26(44,8)$ & 0,001 \\
\hline $\begin{array}{l}\text { Tyrimai dèl feoch- } \\
\text { romocitomos }\end{array}$ & $13(48,1)$ & $43(51,8)$ & 0,741 & $2(7,4)$ & $25(43,1)$ & 0,001 \\
\hline $\begin{array}{l}\text { Pacientai, ku- } \\
\text { riems nustačius } \\
\text { darinị antinkstyje, } \\
\text { hormonų tyrimai } \\
\text { nebuvo atlikti }\end{array}$ & $8(29,6)$ & $12(14,5)$ & 0,076 & $13(48,1)$ & $11(19)$ & 0,005 \\
\hline
\end{tabular}

5 lentelè. Antinksčių darinių, nustatytų 2010 ir 2014 metais, hormoninis aktyvumas

\begin{tabular}{|l|c|c|c|}
\hline & $\begin{array}{c}\mathbf{2 0 1 0} \mathbf{~ m .} \\
\mathrm{N}=54 \\
\mathrm{~N}(\%)\end{array}$ & $\begin{array}{c}\mathbf{2 0 1 4} \mathbf{~ m .} \\
\mathrm{N}=141 \\
\mathrm{~N}(\%)\end{array}$ & $\begin{array}{c}\text { Iš viso } \\
\mathrm{N}=195 \\
\mathrm{~N}(\%)\end{array}$ \\
\hline $\begin{array}{l}\text { Nesekretuojanti } \\
\text { adenoma }\end{array}$ & $46(85,2)$ & $120(86,3)$ & $166(86,0)$ \\
\hline Aldosteroma & $2(3,7)$ & $10(7,2)$ & $12(6,2)$ \\
\hline Feochomocitoma & $4(7,4)$ & $6(4,3)$ & $10(5,2)$ \\
\hline $\begin{array}{l}\text { Kušingo sindro- } \\
\text { mas }\end{array}$ & $1(1,9)$ & $2(1,4)$ & $3(1,6)$ \\
\hline Karcinoma & $0(0,0)$ & $0(0,0 \%)$ & $0(0,0)$ \\
\hline Metastaze & $1(1,9)$ & $0(0,0)$ & $1(0,5)$ \\
\hline Recidyvas & $0(0,0)$ & $1(0,7)$ & $1(0,5)$ \\
\hline
\end{tabular}

- klinikinius simptomus: simptominiai - turintys arterinę hipertenziją ir/ar arterinio kraujo spaudimo pakilimo epizodus, ir/ar svorio didejimą, ir/ar hipokalemiją ir besimptomiai - neturintys būdingų simptomų.

Pacientų duomenys koduoti ir sisteminti „Microsoft Excel“" programos lenteleje. Statistinè duomenų analizė atlikta IBM SPSS Statistics 23.0.0 programa. Kategoriniu duomenu analizei naudotas asimptominis ir tikslus $\chi^{2} \mathrm{kri}-$ terijus. Dviejų grupių palyginimui taikytas Stjudent'o T testas arba Mann - Whitney U testas. Daugiau nei dviejų vidurkių palyginimui taikyta dispersine analizė ANOVA ir daugkartiniai poriniai palyginimai. Hipotezių patikrinimui naudotas statistinio reikšmingumo lygmuo $\alpha=0,05$. Vertinta, kad statistiškai reikšmingų skirtumų yra bent tarp dviejų tiriamų grupių, jei testo apskaičiuota p reikšmè mažesnè už 0,05 . Tolydiesiems kintamiesiems įvertinti naudotas vidurkis ir jo standartinis nuokrypis.

\section{Rezultatai}

Taikant minètus TLK10-AM kodus, i tyrimą buvo atrinkti 89 pacientai 2010 ir 294 - 2014 metais. Šimtui devyniasdešimt penkiems pacientams dariniai antinksčiuose buvo nustatyti pirmą kartą: iš jų 54 2010 metais ir 141 - 2014 metais, todèl jie buvo įtraukti į tolesnę analizę. Ketvirtadali tiriamujjų sudare vyrai, vidutinis pacientų amžius buvo $60,7 \pm 12,8$ metai. Daugiau kaip du trečdaliai darinių antinksčiuose buvo rasti atsitiktinai ir apie puse jų nesukèlè jokių simptomų. Pagrindinès pacientų ir antinksčių darinių charakteristikos reikšmingai nesiskyrè lyginant 2010 ir 2014 metus (1 lentelè).

Didžioji dauguma darinių antinksčiuose buvo nustatyta KT tyrimu. MRT buvo taikytas tik 2014 metais dešimčiai pacientų ir tai buvo vienintelis radiologinio ištyrimo skirtumas tarp grupių. Vidutinis antinksčiu darinių dydis siekè apie $20 \mathrm{~mm}$ ir pagal lokalizaciją 2010 ir 2014 metais nesiskyrè (2 lentelè).

Pirmą kartą nustatytų dariniu antinksčiuose ištyrimas dèl galimo hormoninio aktyvumo 2014 metais buvo reikšmingai dažnesnis: buvo atlikta beveik dvigubai daugiau tyrimų dèl aldosteromos ir feochromocitomos, lyginant su 2010. Taip pat svarbu, kad 2010 metais taikytą adrenalino ir noradrenalino tyrimą paros šlapime 2014 pakeite metanefrino ir normetanefrino tyrimai kraujyje, kurie buvo atlikti daugiau nei pusei pacientų. Hiperaldosteronizmo vertinimui 2014 metais daugiau kaip 45\% pacientų tirtas aldosteronas ir reninas, lyginant su atitinkamai kiek daugiau nei 27 ir 18\% minètų tyrimų 2010. Pacientai, kuriems nebuvo atliktas nei vienas hormoninis tyrimas 2014 metais sudare $16,3 \%$ ir tai buvo daugiau nei dvigubai mažiau, lyginant su $38,9 \% 2010(p<0,001)$. Pacientams atlikti hormonų tyrimai pateikiami 3 lenteleje.

Hormonų tyrimų atlikimo dažnio padidẻjimas 2014 metais stebimas visiems pacientams neatsižvelgiant $i ̣$ tai, ar jie turejjo simptomų, ar ne. Simptomų turintiems pacientams 2014 metais buvo atliekama dvigubai daugiau tyrimų dèl itariamo Kušingo sindromo ir hiperaldosteronizmo, o dèl galimos feochromocitomos ištyrimo dažnis 2010 ir 2014 metais beveik nesiskyrè. Besimptomiams pacientams 2010 ir 2014 metais tyrimų dèl ịtariamo Kušingo sindromo buvo atliekama vienodai dažnai, 2014 metais du kartus daugèjo aldosterono tyrimų atlikimo dažnis, šešis kartus padaugejo renino tyrimų atlikimo dažnis ir šešis kartus - tyrimų dèl itariamos feochromocitomos atlikimo dažnis. Besimptomių pacientų grupejje 2010 metais stebimas ryškus aldos- 
terono ir renino tyrimų atlikimo dažnio nesutapimas, tačiau 2014 metais šie tyrimai buvo atliekami visada kartu. Laborotorinių tyrimų atlikimo dažnis simptominiams ir besimptominiams pacientams plačiau pateikiamas 4 lenteleje.

Ivvertinus antinksčių darinių hormoninį aktyvumą nustatyta, kad 2014 metais ženkliai pagerejjo aldosteromų išaiškinimas - jų diagnozuota penkis kartus daugiau nei 2010 metais. Feochromocitomų ir Kušingo sindromo dažnis koreliavo su ištirtų pacientų skaičiumi (5 lentelè).

Operacinis gydymas buvo taikytas $4(8,7 \%)$ ir $1(0,8 \%)$ nesekretuojančiam antinksčių dariniui, $2(100 \%)$ ir 4 (40 $\%)$ aldosteromoms, $4(100 \%)$ ir $4(66,7 \%)$ feochromocitomoms atitinkamai 2010 ir 2014 metais. Nesekretuojančios adenomos buvo operuojamos dèl dydžio, kuris buvo panašus 2010 ir 2014 metais - atitinkamai 38,5 $\pm 26,5$ ir 36,2 $\pm 17 \mathrm{~mm}$., o neoperuoti antinksčių dariniai - stebimi. Hiperaldosteronizmo atveju neoperuotiems pacientams buvo taikytas medikamentinis gydymas.

\section{Rezultatų aptarimas}

Vis plačiau taikant modernius pacientų ištyrimo metodus, nustatoma daugiau darinių antinksčiuose. Dažniausiai pas specialistus patenka pacientai, kuriems darinys antinkstyje randamas atsitiktinai, todèl ligos anamnezè ir simptomai apsprendžia tolesnę tyrimo taktiką. Kadangi hormonus sekretuojančios adenomos ne visada turi ryškius klinikinius simptomus, visus pacientus rekomenduojama tirti dèl subklinikinio Kušingo sindromo ir feochromocitomos [9]. Tai galima pastebèti ir mūsų klinikoje - dažnejja atliekamų tyrimų besimptomiams pacientams dèl feochromocitomos bei daugeja kitų tyrimų.

Palyginus mūsų duomenis su Kroatijos referentinio centro duomenimis, pagal nustatytų antinksčių darinių hormoninį aktyvumą, sutapo, kad dauguma adenomų buvo hormonų nesekretuojančios (72,4\% lyginant su 86,0\%), tačiau kiti rezultatai išsiskyrè. Dažniausias jų klinikoje iš hormonus sekretuojančių adenomų buvo subklinikinis Kušingo sindromas, nustatytas net $11,3 \%$ pacientų. Mūsų klinikoje šis dažnis gerokai mažesnis $-1,6 \%$ ir nedideja. Tikètina, kad taip yra dèl to, kad šie pacientai neturi tipiškų nusiskundimų, dažniausiai tiriamas rytinis kortizolis, o $1 \mathrm{mg}$ deksametazono supresijos testas atliekamas retai. Šiuo metu pacientų ištyrimas yra labiau konkretizuotas, nes sukurtas ligonių ištyrimo algoritmas - nustačius darinį antinkstyje visiems rekomenduojama atlikti $1 \mathrm{mg}$ deksametazono supresijos mėginį, todèl tikimès, kad šių išaiškinamumas turètų išaugti. Aldosteromų ir feochromocitomų dažniai panašūs - esant šiems dariniams dažnesni būdingi klinikiniai simptomai, todèl pacientai ištiriami detaliau [14].

Lyginant tiriamųjų pasiskirstymą pagal lytị su Korejos retrospektyvinio tyrimo duomenimis, (J. Kim ir kt. (2013), kuriame 348 tiriamiesiems atlikus KT tyrimą dèl kitos su antinksčiais nesusijusios patologijos, nustatyti dariniai antinksčiuose, abiejuose tyrimuose stebimas didesnis antinksčių darinių paplitimas tarp moterų [15]. Tačiau kitų studijų duomenimis, antinksčių darinių paplitimas autopsijų radiniuose tarp vyrų ir moterų nesiskyrè $[16,17]$. Lyginant mūsų ir japonų multicentrinio retrospektyvinio tyrimo (Y. Tabuchi ir kt. (2016) duomenis darinių antinksčiuose radiologiniai nustatymo būdai sutapo, daugiausia darinių nustatyta KT, ženkliai mažiau UG ir MR tyrimais [18]. Vidutinis antinksčių darinio dydis taip pat atitinka mūsų centro duomenis (mūsų tyrime 21,7 $\pm 14,2 \mathrm{~mm}$, Y. Tabuchi ir kt. (2016) tyrime $21,1 \pm 10,6 \mathrm{~mm}$ ) [18]. Mūsų tyrimo duomenimis, antinksčių darinių lokalizacija kairejje ar dešinèje pusèje buvo panaši (43,0\% ir 39,9\%), o Korejos ir Japonijos tyrimo duomenimis, antinksčių dariniai dažniau nustatyti kairèje ( $62,0 \%$ ir 57,0\% atitinkamai). Literatūros duomenimis, apytiksliai 10\% darinių nustatoma abiejuose antinksčiuose, dažniausiai dèl ịgimtos antinksčiu hiperplazijos ar naviko metastazių antinksčiuose [19, 20]. Mūsų ir J. Kim ir kt. (2013) tyrime stebimas panašus funkciškai aktyvių antinksčių darinių dažnis (14\% ir 17,8\% atitinkamai). Mūsų tyrimo duomenimis, $2010 \mathrm{~m}$. vyravo feochromocitomos (7,4\%), o $2014 \mathrm{~m}$. aldosteromos (7,2\%), korejiečių tyrimo duomenimis, daugiausia nustatoma feochromocitomų (7,2\%).

Mūsų tyrimo duomenimis, apie pusè pacientų, kuriems buvo nustatyti dariniai antinksčiuose turejo nusiskundimų, vyraujantis simptomas buvo hipertenzija, ja skundèsi 40,7\% pacientų 2010 metais ir 50,4\% pacientų 2014 metais, LSMUKK Endokrinologijos klinikos duomenimis, $60 \%$ pacientų nukreiptų endokrinologo konsultacijai dèl ịtariamo darinio antinksčiuose turejo padidejusi arterinị kraujo spaudimą [21].

Analizuojant mūsų tyrimo rezultatus, stebima hormoninų tyrimų atlikimo didejjimo tendencija: $2010 \mathrm{~m}$. tirta $61,1 \%$ pacientu, 2014 metais $-83,7 \%$. Ankstesni, mažesnès imties VULSK pacientų su antinksčių dariniais stebejimų rezultatai atspindi tą patị [22]. Tiek mūsų tyrimo, tiek anksčiau atlikto VULSK tyrimo duomenimis, hormoniniai tyrimai dažniau atliekami simptomų turintiems pacientams [22].

Mūsų tyrimas parodè, kad antinksčių dariniai nustatomi vis dažniau. Dalis jų būna klinikiniais simptomais ir požymiais nepasireiškiančios hormoniškai aktyvios adenomos, todèl reikia gerai ịvertinti paciento būklę ir paskirti reikiamą ištyrimą.

\section{Išvados}

1. Didžioji dauguma darinių antinksčiuose buvo nustatyti atliekant KT. 
2. Pusei pacientų dariniai antinksčiuose nesukèlė jokių simptomų.

3. Hormoninis antinksčių darinių ištyrimas reikšmingai dažniau buvo atliekamas 2014, lyginant su 2010 metais.

4. Pagerejus hormoniniam ištyrimui, 2014 metais nustatyta dvigubai daugiau aldosteromų nei 2010 metais, kitu hormoniškai aktyvių darinių dažniai nesiskyrè.

\section{Literatūra}

1. Grumbach MM, Biller BM, Braunstein GD, Campbell KK, Carney JA, Godley PA, Harris EL, Lee JK, Oertel YC, Posner MC, Schlechte JA \& Wieand HS. Management of the clinically inapparent adrenal mass ("incidentaloma"). Annals of Internal Medicine 2003;138:424-429.

https://doi.org/10.7326/0003-4819-138-5-200303040-00013

2. Kloos RT, Gross MD, Francis IR, Korobkin M \& Shapiro B. Incidentally discovered adrenal masses. Endocrine Reviews 1995; 16:460-484.

3. Mansmann G, Lau J, Balk E, Rothberg M, Miyachi Y \& Bornstein SR. The clinically inapparent adrenal mass: update in diagnosis and management. Endocrine Reviews 2004;25:309340.

https://doi.org/10.1210/er.2002-0031

4. Barzon L, Sonino N, Fallo F, Palu G, Boscaro M. Prevalence and natural history of adrenal incidentalomas. European Journal of Endocrinology 2003;149:273-285.

https://doi.org/10.1530/eje.0.1490273

5. Bovio S, Cataldi A, Reimondo G,Sperone P, Novello S, Berruti A, Borasio P, Fava C, Dogliotti L, Scagliotti GV, Angeli A, Terzolo M. Prevalence of adrenal incidentaloma in a contemporary computerized tomography series. Journal of Endocrinological Investigation 2006;29:298-302.

https://doi.org/10.1007/BF03344099

6. Song JH, Chaudhry FS, Mayo-Smith WW. The incidental adrenal masson ct: prevalence of adrenal disease in 1,049 consecutive adrenal masses in patients with no known malignancy. American Journal of Roentgenology 2008;190:1163-68. https://doi.org/10.2214/AJR.07.2799

7. Terzolo M, Stigliano A, Chiodini I, Loli P, Furlani L, Arnaldi G, Reimondo G, Pia A, Toscano V, Zini M, Borretta G, Papini E, Garofalo P, Allolio B, Dupas B, Mantero F, Tabarin A, Italian Association of Clinical Endocrinologists. AME position statement on adrenal incidentaloma. European Journal of Endocrinology 2011;164(6):851.

https://doi.org/10.1530/EJE-10-1147

8. Kapoor A, Morris T, Rebello R. Guidelines for the management of the incidentally discovered adrenal mass. Can Urol Assoc J 2011;5(4):241-7.

https://doi.org/10.5489/cuaj.11135

9. Fassnacht M, Arlt W, Bancos I,Dralle H, Newell-Price J, Sahdev A, Tabarin A, Terzolo M, Tsagarakis S, Dekkers OM.
Management of adrenal incidentalomas: European Society of Endocrinology Clinical Practice Guideline in collaboration with the European Network for the Study of Adrenal Tumors. European Journal of Endocrinology 2016;175:G1-G34.

https://doi.org/10.1530/EJE-16-0467

10. Zeiger MA, Thompson GB, Duh QY, Hamrahian AH, Angelos P, Elaraj D, Fishman E, Kharlip J. AACE/AAES Adrenal incidentaloma guidelines. Endocrine Practice 2009;15.

11. Cawood TJ, Hunt PJ, O'Shea D, Cole D, Soule S. Recommended evaluation of adrenal incidentalomas is costly, has high false-positive rates and confers a risk of fatal cancer that is similar to the risk of the adrenal lesion becoming malignant; time for a rethink? European Journal of Endocrinology 2009;161:513-27. https://doi.org/10.1530/EJE-09-0234

12. Sawka AM, Jaeschke R, Singh RJ, Young WF Jr. A comparison of biochemical tests for pheochromocytoma: Measurement of fractionated plasma metanephrines compared with the combination of 24-hour urinary metanephrines and catecholamines. The Journal of Clinical Endocrinology and Metabolism 2003;88:553-8.

https://doi.org/10.1210/jc.2002-021251

13. Lenders JWM, Pacak K, Eisenhofer G. New advances in the biochemical diagnosis of pheochromocytoma: Moving beyond catecholamines. Annals of New York Academy of Sciences 2002;970:29-40.

https://doi.org/10.1111/j.1749-6632.2002.tb04410.x

14. Kastelan D, Kraljevic I, Dusek T, Knezevic N, Solak M, Gardijan B, Kralik M, Poljicanin T, Skoric-Polovina T, Kastelan $Z$. The clinical course of patients with adrenal incidentaloma: is it time to reconsider the current recommendations? Eur J Endocrinol 2015;173(2):275-82.

https://doi.org/10.1530/EJE-15-0199

15. Kim J, Bae KH, Choi YK, Jeong JY, Park KG, Kim JG, Lee IK. Clinical characteristics for 348 patients with adrenal incidentaloma. Endocrinol Metab (Seoul) 2013; 28(1):20-25. https://doi.org/10.3803/EnM.2013.28.1.20

16. Russell RP, Masi AT, Richter ED. Adrenal cortical adenomas and hypertension. A clinical pathologic analysis of 690 cases with matched controls and a review of the literature. Medicine (Baltimore) 1972;51:211-25.

https://doi.org/10.1097/00005792-197205000-00007

17. Grumbach MM, Biller BM, Braunstein GD, Campbell KK, Carney JA, Godley PA, Harris EL, Lee JK, Oertel YC, Posner MC, Schlechte JA, Wieand HS. Management of the clinically inapparent adrenal mass ("incidentaloma"). Ann Intern Med 2003;138:424-9.

https://doi.org/10.7326/0003-4819-138-5-200303040-00013

18. Tabuchi Y, Otsuki M, Kasayama S, Kosugi K, Hashimoto K, Yamamoto T, Tsugawa M, Mineo I, Yamada Y, Kurebayashi S, Ohashi M, Umayahara Y, Kouhara H, Nakamura T, Taki H, Matsuoka TA, Imagawa A, Funahashi T, Shimomura I. Clinical and endocrinological characteristics of adrenal incidentaloma 
in Osaka region, Japan. Endocr J 2016; 63(1):29-35.

https://doi.org/10.1507/endocrj.EJ15-0404

19. Mantero F, Terzolo M, Arnaldi G, Osella G, Masini AM, Ali A, Giovagnetti M, Opocher G, Angeli A. A survey on adrenal incidentaloma in Italy. Study group on adrenal tumors of the italian society of endocrinology. J Clin Endocrinol Metab 2000;85:637-44.

20. Latronico AC, Chrousos GP. Extensive personal experience: adrenocortical tumors. J Clin Endocrinol Metab 1997; 82:131724.

21. Banišauskaitė I., Jurevičiūtė J., Matulevičiūtė I., Barsienė L., Visockienė Ž., Verkauskienė R., Matulevičius V., Ostrauskas R. Antinksčiu incidentalioma. Situacija Lietuvoje. Lietuvos endokrinologija, 2013;21(1,2,3,4):102-105.

22. Visockienė Ž., Girdžiūtė M., Juškienė R. Antinksčių incidentalomu stebèjimas Vilniaus universiteto ligoninèje Santaros klinikose - dvejų metų rezultatai. Lietuvos endokrinologija, 2014;22(1,2,3,4):35-40.

\section{ADRENAL MASSES DIAGNOSED FOR THE FIRST TIME: COMPARISON OF ASSESSMENT STRATEGY IN 2010 AND 2014 AT VILNIUS UNIVERSITY HOSPITAL SANTARA CLINICS}

\section{L. Ščerbinskaitė, A. Bradulskytė, M. Girdžiūtė, V. Guntaitė,} Ž. Visockienė

Key words: adrenal masses, computed tomography, an overnight dexamethasone suppression test, plasma-free metanephrines, aldosteronoma.

Summary

Background. Adrenal masses are common finding in abdominal scaning. In order to determine functional activity hormonal testing is required.
Objective. The aim of the study was to compare the assessment strategy in patients for the first time diagnosed with adrenal masses at Vilnius University Hospital Santariskiu Clinics in 2010 and 2014.

Methods. There were 383 cases with adrenal masses diagnosed at the mentioned time points, 195 - for the first time and thus included into further analysis. All subjects were grouped into symptomatic (arterial hypertension and/or episodic elevations of blood pressure, and/or weight gain, and/or hypokalemia) and asymptomatic as well as those with incidentally or purposively discovered masses. All adrenal masses were assessed for hormonal activity.

Results. More than two-thirds of adrenal masses were found incidentally, and about half of them did not cause any symptoms. The main characteristics of patients and adrenal masses did not differ significantly comparing 2010 and 2014. The average size of adrenal masses were $23,8 \pm 16,7 \mathrm{~mm}$ in 2010 and $20,8 \pm 13,0 \mathrm{~mm}$ in 2014. There was higher frequency of hormonal testing that resulted in almost twice more aldosteromas diagnosed in 2014 compared to 2010, but not other secreting adrenal tumors.

Conclusions. The vast majority of patients with adrenal masses did not have any symptoms and masses were discovered incidentally. The higher frequency of hormonal testing in 2014 led to diagnosis of almost twice more aldosteronomas, but not other secreting adrenal tumors.

Correspondence to: scerbinskaite.lina@gmail.com

Gauta 2017-03-28 